\title{
Feeding and reproduction in a small calanoid copepod: Acartia clausi can compensate quality with quantity
}

\author{
Danilo Calliari $^{1, *}$, Peter Tiselius ${ }^{2}$ \\ ${ }^{1}$ Sección Oceanología, Facultad de Ciencias, Universidad de la República, Iguá 4225, CP 11400, Montevideo, Uruguay \\ ${ }^{2}$ Department of Marine Ecology, Göteborg University, Kristineberg Marine Research Station, Fiskebäckskil 450 34, Sweden
}

\begin{abstract}
We analyzed the feeding, egg production rate (EPR), and the egg hatching success (EHS) of resulting eggs of adult Acartia clausi subject to realistic food levels $\left(100 \mu \mathrm{g} \mathrm{C}^{-1}\right)$ of 7 algae. Feeding was maximum (ca. $20 \mathrm{ml}$ ind. ${ }^{-1} \mathrm{~d}^{-1}$ ) with Thalassiosira weissflogii and minimum (ca. $0 \mathrm{ml}$ ind. ${ }^{-1} \mathrm{~d}^{-1}$ ) with Dunaliella tertiolecta and Prymnesium parvum. EPR was highest with T. weissflogii, Tetraselmis sp., Rhodomonas sp., and Ditylum brightwellii (21 to 26 eggs ind. ${ }^{-1} \mathrm{~d}^{-1}$ ) and moderate with Prorocentrum minimum (15 eggs ind.-1 $\left.\mathrm{d}^{-1}\right)$. EHS was highest in P. minimum (84\%), followed by Rhodomonas sp. (80\%), D. brightwellii (60\%), T. weissflogii (52\%) and Tetraselmis sp. (40\%). Supplementary nutritional effects (higher EHS and gross growth efficiency) appeared when A. clausi fed on mixtures of algae with contrasting effects on EPR and EHS ( $T$. weissflogii and P. minimum) offered as mixed suspensions, or alternating between unialgal suspensions on a 12:12 h basis. However, realized fecundity (RF) was fairly stable for most single and mixed diets (range 12.3 to 17.3 nauplii female $\mathrm{e}^{-1} \mathrm{~d}^{-1}$ ), with the exception of Tetraselmis sp. (8.9 nauplii female $\mathrm{e}^{-1} \mathrm{~d}^{-1}$ ). Such stable RF was attained by compensating low EHS with enhanced feeding and EPR, and consequently lower population growth efficiency. That represents a strategy with a high cost in terms of metabolism and predation risk.
\end{abstract}

KEY WORDS: Acartia clausi $\cdot$ Reproduction $\cdot$ Food quality $\cdot$ Diatoms $\cdot$ Nutrition deficiency Resale or republication not permitted without written consent of the publisher

\section{INTRODUCTION}

Interest in copepod-food interactions has notably increased during the last years. Early results suggesting that diatoms could induce embryo mortality (Kleppel et al. 1991, Poulet et al. 1995, Ianora et al. 1996) challenged their role in marine food webs and boosted research into the effects of food quality on copepod production and reproductive success. Field observations (Miralto et al. 1999, Miralto et al. 2003) and laboratory experiments (Chaudron et al. 1996, Kang \& Poulet 2000, Turner et al. 2001) suggested that certain diatoms may indeed arrest copepod egg development. Thus, while diatoms may favour high egg production rates (EPR), the reproductive output of copepods feeding on a diatom-dominated diet would be seriously compromised by a very low egg hatching success (EHS).
However, EPR and EHS responses were highly variable among experimental studies involving different copepod-algae combinations (Ban et al. 1997). Furthermore, in situ dominance by diatoms in the plankton and in the diet is not necessarily associated with impairment in copepod reproductive output (Irigoien et al. 2000, 2002). This appears to contradict results reported elsewhere (i.e. Poulet et al. 1994, Miralto et al. 2003), and the debate is still open.

Several possible causes may lay behind apparently inconsistent results. Negative effects of diatoms were typically found in experiments at unrealistically high food levels (i.e. $1000 \mu \mathrm{g} \mathrm{C}^{-1}$ ); also, the concentration of aldehydes shown to affect embryogenesis was orders of magnitude too high compared with those copepods may experience in the field (Poulet et al. 1994, Ianora et al. 1995). Other potential drawbacks of 
experimental studies are that actual ingestion was seldom measured (i.e. Poulet et al. 1994, Chaudron et al. 1996, Ban et al. 1997), while food levels among treatments were not always comparable. Inadequacies of experimental designs do not allow the detection of whether observed EPR and/or EHS responses were due to nutritional deficiencies or to the presence of toxic compounds in the tested algae.

Feeding experiments considering mixtures of algae with known and contrasting effects on EPR and EHS are a potential tool for discriminating between nutritional deficiency and toxic effects (Jónasdóttir et al. 1998). EPR and EHS responses are measured in animals subject to carefully controlled (and non-saturating) food availability along an experimental mixing gradient between a $100 \%$ 'good' alga and a $100 \%$ 'suspect' alga. In the simplest case, if the suspect alga is nutritionally deficient, the response will fall on a reference line connecting the extremes of the gradient (i.e. the response is proportional to the amount of food ingested from each alga). If observed responses fall below the reference line, the suspect alga is toxic, while responses above the reference line evidence complementary nutritional effects (and absence of toxicity). Further details in the interpretation of possible outcomes can be found in Jónasdóttir et al. (1998). This approach has been recently employed to test toxic effects of several algal strains to Acartia tonsa (Colin \& Dam 2002).

The design also provides information that is ecologically relevant with respect to food quality. Diversity of natural phytoplankton assemblages, the patchy distribution of food (i.e. Bjørnsen \& Nielsen 1991, Castro et al. 1991) and behavioural traits of copepods (i.e. vertical migration) may add to a wide variability in food quality on a circadial scale. For small copepods the time to produce eggs is close to $24 \mathrm{~h}$ (Kiørboe et al. 1985, Stearns et al. 1989, Tester \& Turner 1990). It is not obvious which effect temporal variability in food quality would have on EPR and EHS, although responses can be expected to integrate the feeding conditions during that period.

Here we report the response of Acartia clausi feeding, EPR and EHS when subject to monospecific diets of different types of algae offered at controlled and realistic food levels. None of the A. clausi-algae combinations reported here had been tested before in terms of their concurrent effects on feeding, EPR, and EHS. One of the algae tested, the diatom Thalassiosira weissflogii, has been reported to induce a lower EPR and EHS in Acartia steueri and Temora longicornis, and decreased EHS in Calanus helgolandicus (Ban et al. 1997). We tested the mixture of a diatom (which induced high EPR and low EHS) with a similarly sized dinoflagellate (that induced lower EPR but higher
EHS) offered either as a combined suspension or in an alternating regime between single-alga incubations. Our objectives were to assess whether negative effects observed with single-alga diets resulted from toxicity of the diatom diet or from nutritional inadequacy, and to explore the existence of nutritional complementarities between the combined algae. Given current uncertainty in relation to the proposed action mechanism of toxic compounds, we did not search for specific potentially toxic substances in the tested algae but based our analysis on the response pattern of A. clausi to the algal mixing experimental design (sensu Jónasdóttir et al. 1998); for instance, T. weissflogii would be considered toxic to A. clausi embryonic viability if a Type 2 response was found in the mixing diagram (Jónasdóttir et al. 1998, Colin \& Dam 2002). Also, we explored the feeding selectivity of $A$. clausi when offered suspensions of 2 mixed algal types and the ability of this copepod to integrate the food intake when subject to a shifting regime on a $24 \mathrm{~h}$ basis.

\section{MATERIALS AND METHODS}

We made 2 types of experiments: one series where single algae were tested over several days, and a second approach where a mixture of algae was presented to the copepods either simultaneously (MIX) or by alternating (ALT).

Single-alga experiment. In the first series, we measured the feeding (as filtering rate), EPR, and EHS response of Acartia clausi to single-alga suspensions. Copepods were obtained from cultures maintained at 18 to $21^{\circ} \mathrm{C}$ and routinely fed a mixture of Thalassiosira weissflogii and Rhodomonas sp., and occasionally Tetraselmis sp. Between 10 and 15 recently moulted $(<7$ d) adult females were transferred to $625 \mathrm{ml}$ bottles and placed on a rotating wheel $(0.2 \mathrm{rpm})$. Algal prey were grown at $18^{\circ} \mathrm{C}$ in batch cultures using B1 medium + vitamins under a 12:12 h (light:dark) illumination regime provided by cool white fluorescent lamps. Algae for experiments were obtained during exponential growth phase at densities between ca. 10 and $25 \mu \mathrm{g} \mathrm{C} \mathrm{ml}^{-1}$. Residual nitrogen concentration in cultures was $>900 \mathrm{\mu mol} \mathrm{l}^{-1}$ (between 77 and $90 \%$ of initial levels) according to stoichiometric calculations of nutrient input to culture medium and nutrient usage by algae, assuming algal biomass composition follows an approximate Redfield ratio of 106:16:1 (carbon, nitrogen, phosphorus, respectively). Such residual nutrient levels confirmed that algae were never nutrient-limited, and that the overall procedure ensured a consistent quality within species and suitable conditions for comparison between species.

Nominal algal concentration in experimental bottles was $100 \mu \mathrm{g} \mathrm{Cl}^{-1}$ (observed range 101 to $109 \mathrm{\mu g} \mathrm{C}^{-1}$ ), 
a food level below saturation for Acartia clausi (Gismervik \& Andersen 1997, Dutz 1998). Carbon content of the algae was estimated based on biovolume measurements as equivalent spherical diameter (ESD) with an electronic particle analyzer (Elzone 5380) and equations in Mullin et al. (1966). Tested algae were the diatoms Thalassiosira weissflogii (TW, Bacillariophyceae, 11.6 $\mathrm{m}$ ESD) and Ditylum brightwellii (DIT, Bacillariophyceae, $18.1 \mu \mathrm{m}$ ESD), the autotrophic dinoflagellate Prorocentrum minimum (PRO, Dinophyceae, $10.4 \mu \mathrm{m} \mathrm{ESD),} \mathrm{and} \mathrm{the} \mathrm{autotrophic} \mathrm{flagellates} \mathrm{Rho-}$ domonas sp. (RHO, Cryptophyceae; $6.9 \mu \mathrm{m}$ ESD), Prymnesium parvum (PRY, Prymnesiophyceae; $5.8 \mu \mathrm{m}$ ESD), Tetraselmis sp. (TETRA, Prasinophyceae; $7.2 \mu \mathrm{m}$ ESD) and Dunaliella tertiolecta (DUN, Chlorophyceae; $5.5 \mu \mathrm{m}$ ESD). All algal strains were provided by the marine algal culture centre at Göteborg University (GUMACC).

Three replicates and 3 controls (algal suspension without copepods) were incubated for each algal treatment. Response variables were measured at $24 \mathrm{~h}$ intervals, and incubations lasted for 3 to $4 \mathrm{~d}$. Every day, incubation bottles were checked for dead animals, which were recorded and picked out.

Algae-mixture experiment. These were designed to provide the copepods with a mixture of 2 algae, either mixed into 1 suspension or kept for $12 \mathrm{~h}$ in one and $12 \mathrm{~h}$ in the other. Experiments were carried out in 11 glass beakers with inserted plastic cylinders with a $100 \mu \mathrm{m}$ mesh net in the bottom, which allowed copepods to move between food suspensions, while eggs and pellets would remain in the beakers. Three replicates and 3 control beakers (algal suspension without copepods) were considered for each algal treatment. The treatments were as follows:

(1) Single alga only (PRO or TW) provided for $12 \mathrm{~h}$ each, with copepods incubated in PRO from noon to midnight and in TW from midnight to noon.

(2) Mixtures of equal carbon amounts of PRO and TW, with copepods moved between freshly prepared mixtures every $12 \mathrm{~h}$.

To keep the algae mixed and in suspension, beakers were gently stirred with a plunger every $6 \mathrm{~h}$. Response variables were measured at $12 \mathrm{~h}$ intervals, and incubations lasted for $4 \mathrm{~d}$.

Feeding was estimated as filtering rate by measuring the algal concentration or particle volume in the algal suspension on the Elzone (5380) particle analyser at the end of the incubations in experimental and control bottles. Since cell volumes of TW and PRO overlap, separation of algae by electronic particle analyses was not possible in mixed algal suspensions. To determine which alga was ingested in the MIX treatment, subsamples of control and experimental bottles were therefore counted under an inverted microscope. Fil- tering rates $\left(\mathrm{F}, \mathrm{ml}\right.$ ind..$\left.^{-1} \mathrm{~d}^{-1}\right)$ were estimated following Frost (1972), and ingestion (I, cells or particle volume ind. ${ }^{-1} \mathrm{~d}^{-1}$ ) was calculated as $\mathrm{I}=\mathrm{F} \times \mathrm{C}$, where $\mathrm{C}$ is average algal concentration.

Egg production and hatching. EPR (eggs ind. ${ }^{-1} \mathrm{~d}^{-1}$ ) was estimated by counting the number of eggs at the end of each incubation (single alga $24 \mathrm{~h}$, mixtures $12 \mathrm{~h}$ but combined with the next incubation to yield a $24 \mathrm{~h}$ result) and transferred to plates with filtered sea water, where the number of nauplii was recorded after $24 \mathrm{~h}$; EHS was expressed as a percentage of the eggs produced over the same period. Cannibalized eggs (evidenced by crumpled egg shells) were considered for EPR calculation but not for estimation of EHS. Temperature during experiments was 18.5 to $20^{\circ} \mathrm{C}$.

After the experiments, copepods were measured (prosome length, PL), and their individual carbon content estimated according to Uye (1982). Size of the animals ranged from 810 to $846 \mu \mathrm{m}$ PL.

An estimate of gross growth efficiency ( $\left.\mathrm{GGE}_{\text {eggs }}\right)$ was obtained as the ratio of carbon produced as eggs to carbon ingested. Production was calculated by converting EPR to carbon units following Kiørboe \& Sabatini (1995). We also estimated the population growth efficiency (PGE, $\mu g$ viable egg $\mathrm{C} \mu \mathrm{g} \mathrm{C}$ ingested ${ }^{-1}$ ) according to Jones et al. (2002).

Pellet production. Pellets were collected in the mixed-algae experiment by sieving the remains from a beaker through a $25 \mu \mathrm{m}$ sieve. A subsample of the pellets was counted and measured (length and width) under a stereo microscope and volume $\left(\mu^{3}\right)$ estimated assuming an ellipsoid shape and volume-to-carbon conversion factor taken from González et al. (1994).

Differences in feeding, EPR and EHS among treatments were tested by 1 -way ANOVA and Tukey HSD post hoc test. Homoscedasticity was verified using the Brown and Forsythe test, and variables transformed when necessary. Comparison between responses in single-alga and mixed-algae experiments were performed by ANCOVA where experimental treatment (single TW, single PRO, TW-PRO alternation and TW-PRO mix) was the categorical factor, and ingestion rate of TW was the continuous predictor (covariate). Comparison of EPR and EHS between treatments (TW-PRO alt vs TW-PRO mix) was performed using Mann-Whitney $U$-test.

\section{RESULTS}

Survival of animals was always high, average number of animals dead during the experiments was $3 \%$ (max. $7 \%$ during DUN experiment). Egg cannibalism was negligible, and ranged between 0 and $2.9 \%$ (average $0.5 \%$ ). 
Table 1. Results of 1-way ANOVA to assess differences in response variables among tested single algal diets. Response variables are filtering rate $\left(\mathrm{ml}\right.$ ind.$\left.^{-1} \mathrm{~d}^{-1}\right)$, specific egg production rate (EPR, $\mu$ g egg $\mathrm{C} \mu \mathrm{g}$ body $\mathrm{C}^{-1}$ ), egg hatching success (EHS, \%), realized fecundity (RF, viable eggs ind.$^{-1} \mathrm{~d}^{-1}$ ) and population growth efficiency (PGE, $\mu$ g viable egg $\mathrm{C} \mu \mathrm{g} \mathrm{C}$ ingested $^{-1}$ ). Letters indicate homogeneous groups according to Turkey HSD post-hoc test

\begin{tabular}{|lcccccc|}
\hline & Filtering & EPR & EHS & GGE $_{\text {eggs }}$ & RF & PGE \\
\hline & $F_{6,71}=30$ & $F_{6,14}=71$ & $F_{4,10}=25$ & $F_{4,10}=6$ & $F_{4,10}=6$ & $F_{4,10}=8$ \\
& $\mathrm{p}<0.01$ & $\mathrm{p}<0.01$ & $\mathrm{p}<0.01$ & $\mathrm{p}<0.05$ & $\mathrm{p}<0.05$ & $\mathrm{p}<0.01$ \\
TW & $\mathrm{A}$ & $\mathrm{A}$ & $\mathrm{A}, \mathrm{B}$ & $\mathrm{A}, \mathrm{B}$ & $\mathrm{A}, \mathrm{B}$ & $\mathrm{A}, \mathrm{B}$ \\
TETRA & $\mathrm{A}, \mathrm{B}$ & $\mathrm{A}, \mathrm{B}$ & $\mathrm{A}$ & $\mathrm{A}$ & $\mathrm{A}$ & $\mathrm{A}$ \\
DUN & $\mathrm{D}$ & $\mathrm{D}$ & & & $\mathrm{A}$ & \\
PRO & $\mathrm{C}$ & $\mathrm{C}$ & $\mathrm{C}$ & $\mathrm{B}$ & $\mathrm{A}, \mathrm{B}$ & $\mathrm{C}$ \\
RHO & $\mathrm{B}, \mathrm{C}$ & $\mathrm{A}, \mathrm{B}$ & $\mathrm{C}$ & $\mathrm{B}$ & $\mathrm{B}$ & $\mathrm{B}, \mathrm{C}$ \\
PRY & $\mathrm{D}$ & $\mathrm{D}$ & & $\mathrm{A}, \mathrm{B}$ & $\mathrm{A}, \mathrm{B}$ & $\mathrm{A}, \mathrm{B}, \mathrm{C}$ \\
DIT & $\mathrm{A}, \mathrm{B}$ & $\mathrm{B}, \mathrm{C}$ & $\mathrm{B}$ & $\mathrm{A}, \mathrm{B}$ \\
\hline
\end{tabular}

suspensions ranged from 11 to $20 \mathrm{ml}$ ind. ${ }^{-1} \mathrm{~d}^{-1}$ (Fig. 4). Filtering rates did not differ between TW and the mixtures, but feeding on PRO was significantly lower (ANOVA, $F_{3,32}=20, \mathrm{p}<<0.01$ ). Feeding on the mixture incubated from noon to midnight was not different from feeding in the mixture incubated from midnight to noon (post hoc Tukey HSD test, $\mathrm{p}=0.98, \mathrm{df}=41$ ). Lowered feeding rates on PRO were thus only a response to the diet, not to the time of incubation.

Filtration rates in mixed-algae experiments (estimated from microscope counts measured on Day 3) for PRO was

\section{Single-alga experiments}

Filtering, EPR, and EHS were significantly different among algae (1-way ANOVA, Table 1). TW, TETRA, and DIT induced higher filtering rates $\left(>12 \mathrm{ml}\right.$ ind..$\left.^{-1} \mathrm{~d}^{-1}\right)$, PRO induced lower filtering rates (4 to $9 \mathrm{ml}$ ind. ${ }^{-1} \mathrm{~d}^{-1}$ ), while DUN and PRY were not fed upon (rates between 2 and $3 \mathrm{ml}$ ind..$^{-1} \mathrm{~d}^{-1}$ ); RHO did not seem to be readily ingested during the first $24 \mathrm{~h}$ of incubation (filtering rate ca. $3 \mathrm{ml}$ ind. ${ }^{-1} \mathrm{~d}^{-1}$ ), but then became increasingly cleared from the suspension (9 to $15 \mathrm{ml}$ ind..$^{-1} \mathrm{~d}^{-1}$ ) (Fig. 1).

EPR ranged between 27 (TW) and 0.8 eggs ind. ${ }^{-1} \mathrm{~d}^{-1}$ (PRY). EPR tended to stabilize after 2 to $3 \mathrm{~d}$. Exceptions were DUN and PRY, where copepods did not feed during the experiments and their EPR decayed over time. In the RHO treatment, EPR decreased first (Day 2) and increased afterwards (Days 3 and 4), reflecting the shift in feeding behaviour with a 24 h delay (Fig. 2).

EHS ranged from rather low (TETRA, 40\%; TW, $52 \%$ ) to moderately high values (RHO, 80\%; PRO, $84 \%$, Fig. 3). GGE eggs varied widely from 0.18 (TETRA) to 0.45 (PRO). RF also differed among algae, with TETRA producing the lowest (8.9 eggs ind..$^{-1} \mathrm{~d}^{-1}$ ) and RHO the highest RF (17.3 eggs ind. ${ }^{-1} \mathrm{~d}^{-1}$ ) (Table 1 ). PGE was affected by algal type, with highest values ( 0.30 to $0.36 \mu \mathrm{g}$ viable egg $\mathrm{C} \mu \mathrm{g} \mathrm{C}$ ingested $^{-1}$ ) for PRO and $\mathrm{RHO}$, and lowest (0.08 to $0.17 \mu \mathrm{g}$ viable egg $\mathrm{C} \mu \mathrm{g}$ $\mathrm{C}_{\text {ingested }}{ }^{-1}$ ) for TETRA, TW and DIT diets.

\section{Mixed-algae experiments}

Filtering rates estimated from particle volume for $12 \mathrm{~h}$ incubations ranged from 16.2 to $19.9 \mathrm{ml}$ ind. ${ }^{-1} \mathrm{~d}^{-1}$ for TW and from 4.7 to $8.8 \mathrm{ml}$ ind..$^{-1} \mathrm{~d}^{-1}$ for PRO, similar to those measured in the corresponding single-alga experiments (16 to $25 \mathrm{ml}$ ind. ${ }^{-1} \mathrm{~d}^{-1}$ in single TW, and 4 to $9 \mathrm{ml} \mathrm{ind.} .^{-1} \mathrm{~d}^{-1}$ in single PRO). Feeding in the mixed
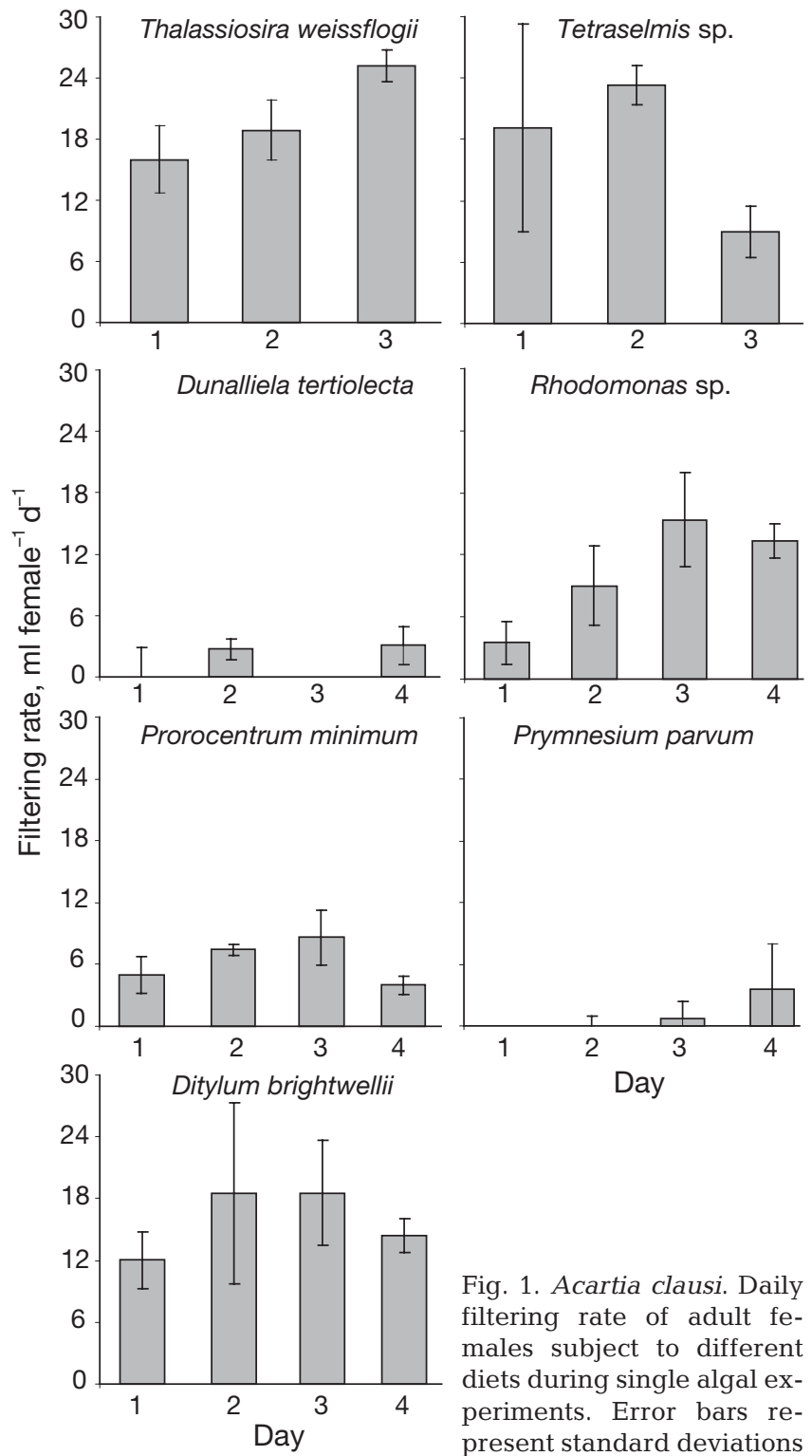

Fig. 1. Acartia clausi. Daily filtering rate of adult females subject to different diets during single algal experiments. Error bars represent standard deviations 

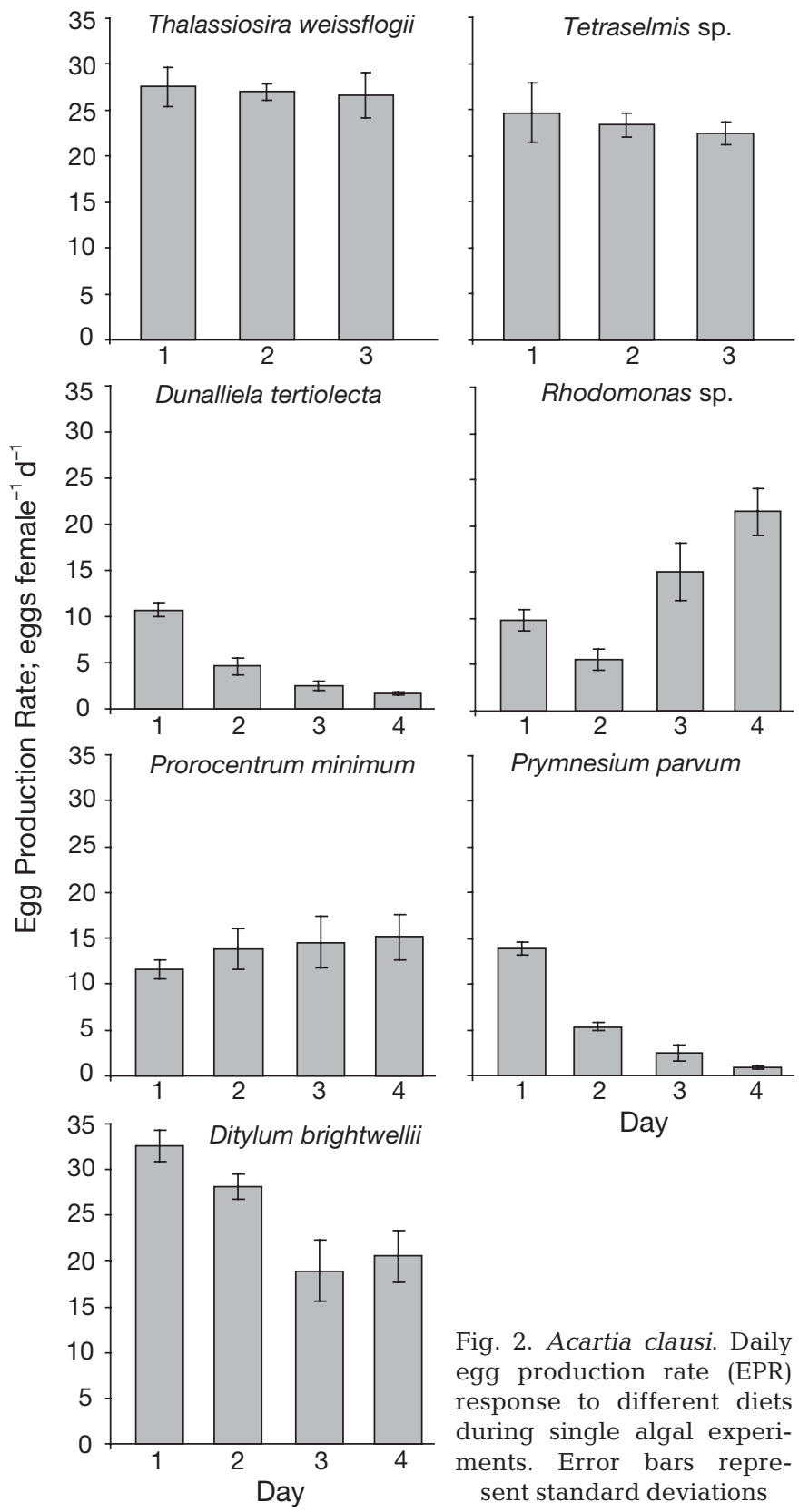

Fig. 2. Acartia clausi. Daily egg production rate (EPR) response to different diets during single algal experiments. Error bars represent standard deviations

$7.5 \pm 2.3 \mathrm{ml}$ ind ${ }^{-1} \mathrm{~d}^{-1}$ and for TW $22.6 \pm 7.6 \mathrm{ml} \mathrm{ind}^{-1} \mathrm{~d}^{-1}$, i.e. the copepods strongly selected TW in the mixture with PRO. Filtration rates for each algal type in the mix were thus very similar to the corresponding single-alga experiments, suggesting a consistent selection for TW irrespective of complimentary food items. Ingestion rates reflected filtering rates with highest ingestion in TW (1.7 to $2.1 \mu \mathrm{g} \mathrm{C}$ ind. ${ }^{-1} \mathrm{~d}^{-1}$ ), lowest in PRO (0.4 to $0.8 \mu \mathrm{g} \mathrm{C}$ ind. ${ }^{-1} \mathrm{~d}^{-1}$ ), and 1.1 to $2 \mu \mathrm{g} \mathrm{C}$ ind..$^{-1} \mathrm{~d}^{-1}$ in the mix (Fig. 4).

Pellet production expressed as carbon (Fig. 4) was significantly higher when the copepods were feeding on TW and mixed diets compared to feeding on PRO $\left(\right.$ ANOVA, $\left.F_{3,44}=5, \mathrm{p}<0.01\right)$.
Egg production was stable over the $4 \mathrm{~d}$ experiments (15 to 21 eggs ind..$^{-1} \mathrm{~d}^{-1}$ ) and did not differ between TW-PRO consecutive treatments and mixtures (MannWhitney test, $U=71, \mathrm{n}=24, \mathrm{p}>>0.05$; Fig. 5). EPR was intermediate compared with the single-alga experiments and significant differences existed between single TW and the other 3 treatments (ANCOVA, $F_{3,8}=51$ and $F_{1,8}=770$, for treatment and covariate, respectively, $\mathrm{p}<0.01$ in both cases). EHS (Fig. 5) did not differ between TW-PRO consecutive treatments and mixtures (Mann-Whitney test, $U=3, \mathrm{n}=6, \mathrm{p}>>0.05$ ) and remained stable around 76 to $90 \%$, similar to the single PRO experiment but significantly higher than the single TW experiment (ANCOVA, $F_{3,8}=158$, and $F_{1,8}=$ 845 , for treatment and covariate, respectively, $\mathrm{p}<0.01$ in both cases). RF was $15.6( \pm 2.3)$ and $12.5( \pm 3.1)$ nauplii fem. ${ }^{-1} \mathrm{~d}^{-1}$ in alternating and mixing incubations, respectively; no significant differences existed among single TW, PRO, alternating and mixing treatments (ANOVA, $F_{3,8}=1.4, \mathrm{p}>0.05$ ). PGE differed among treatments (ANOVA, $F_{3,8}=27, \mathrm{p}<0.01$ ), and values for the single TW experiment $\left(0.13 \mu \mathrm{g} \mathrm{C} \mu \mathrm{g} \mathrm{C}\right.$ ingested $\left.^{-1}\right)$ were lower than PGE for the other 3 diets (range 0.29 to $0.39 \mu \mathrm{g} \mathrm{C} \mu \mathrm{g} \mathrm{C}_{\text {ingested }}{ }^{-1}$ ).

\section{DISCUSSION}

None of the Acartia clausi-algae combinations tested in the present study had been previously reported in terms of joint ingestion, EPR and EHS responses. Results reported here indicate that feeding,

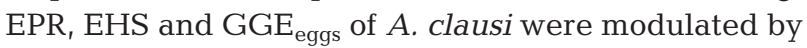
the type of food offered. Furthermore, in several cases those processes were affected in opposite fashion by a given algae (i.e. enhanced EPR and diminished EHS).

\section{Feeding}

Filtering rates varied between moderate and high, except for the flagellates DUN and PRY, which were not ingested. Feeding effort measured as filtration rate was very different in the PRO and TW treatments (Fig. 1). Acartia clausi filtered TW at $20 \mathrm{ml}$ ind. ${ }^{-1} \mathrm{~d}^{-1}$ but PRO was only filtered at $6.3 \mathrm{ml}$ ind. ${ }^{-1} \mathrm{~d}^{-1}$, despite their similar sizes. Interestingly, there was a consistent difference also in the mixed-algae experiment, 22.6 and $7.5 \mathrm{ml}$ ind. ${ }^{-1} \mathrm{~d}^{-1}$ for TW and PRO, respectively. Both species are captured through filtration, and the result implies that the retention is still different between the 2 similarly sized species. The dinoflagellate Prorocentrum minimum is laterally compressed, which means that the effective size may be smaller than the ESD. The diatom Thalassiosira weissflogii, on the other 

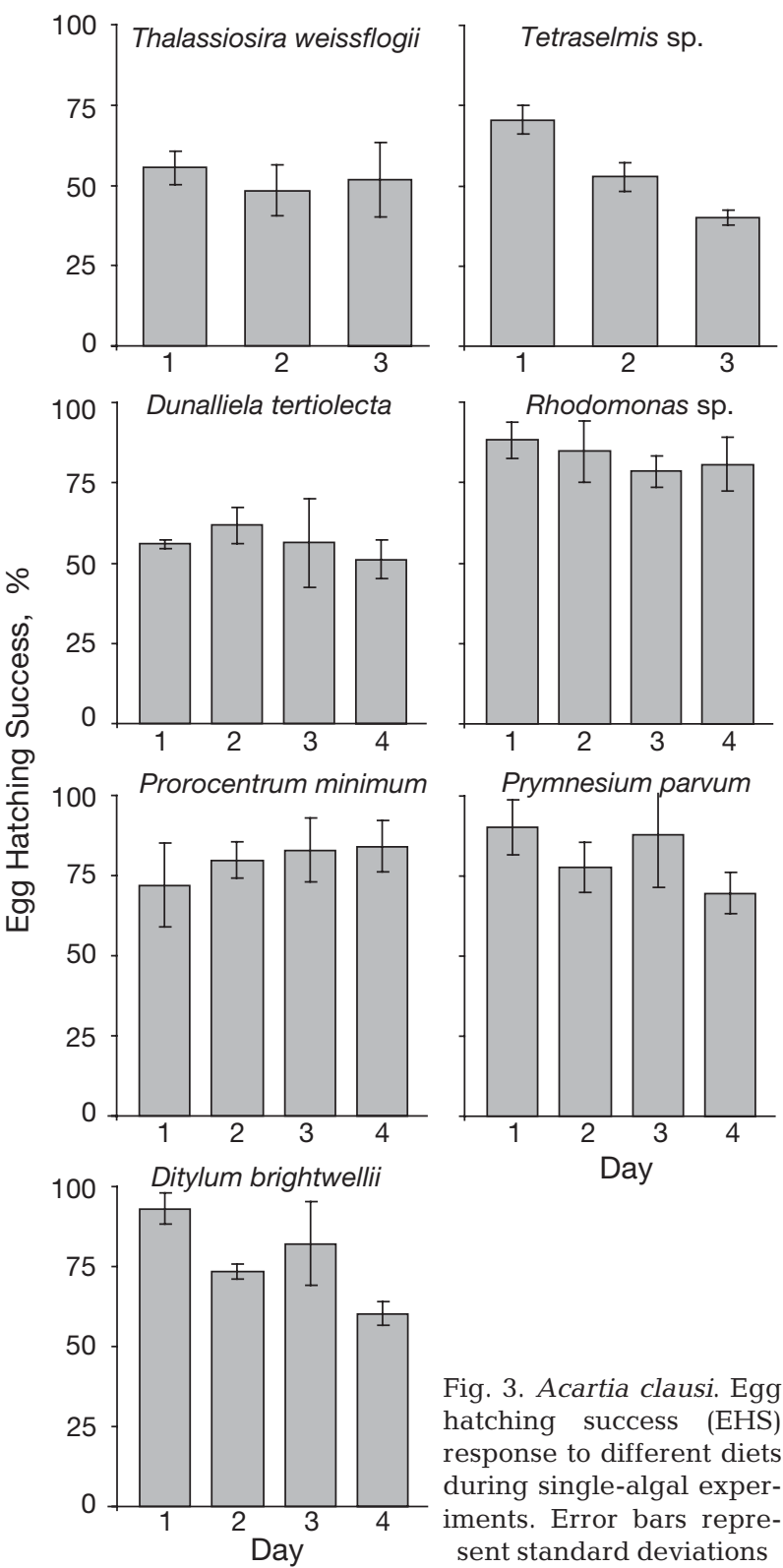

Fig. 3. Acartia clausi. Egg hatching success (EHS) response to different diets during single-algal experiments. Error bars represent standard deviations

hand, have small spines that may increase the apparent size without changing the ESD as measured on the particle counter. However, whether the preference for diatoms displayed by $A$. clausi in our experiments is a consequence of capture mechanisms or a deliberate choice by the animal remains an open question.

\section{Egg production and production efficiency}

TW, TETRA, RHO, and DIT induced high EPR. Observed EPR were in the range reported for Acartia clausi (Dutz 1998, Mauchline 1998), and are consistent with studies that report high EPR when copepods are subject to experimental diatom diets (Calanus helgo-
landicus-Thalassiosira rotula, Chaudron et al. 1996; Temora stylifera-T. rotula, Turner et al. 2001) and to a RHO diet (Acartia tonsa-Rhodomonas baltica, Dutz 1998). EPR correlates to specific polyunsaturated fatty acids (PUFAs) present in the seston (Jónasdóttir et al. 1995, Müller-Navarra et al. 2003), and in the ingested food (Jónasdóttir 1994). PUFAs were reported to be present in high levels in actively growing TW and Rhodomonas lens (Jónasdóttir 1994).

Copepods fed PRO developed significantly lower EPR, which differs from Colin \& Dam (2002), who found no differences in EPR by Acartia tonsa when fed either Thalassiosira rotula or Prorocentrum minimum. In turn, the response of $A$. clausi in our experiments was opposite to the findings of decreased EPR by Calanus helgolandicus (Poulet et al. 1994, Kang \& Poulet 2000), and A. clausi fed T. rotula (Ban et al. 1997). However, decreased EPR in A. clausi fed T. rotula cannot be unambiguously attributed to diatom diets given quite similar EPR reductions in the controls and the lack of data regarding food ingestion during experiments.

GGE $_{\text {eggs }}$ for Acartia clausi (18 to $45 \%$ ) was generally in the range of previous estimates for A. tonsa (e.g. Kiørboe et al. 1985, Berggreen et al. 1988), but lower than the high efficiencies reported for A. clausi by Saiz et al. (1992). The latter found GGE under non-turbulent condition ranging from 61 to $70 \%$. However, egg cannibalism was high (up to $40 \%$ ), and if the re-ingestion had been accounted for, their GGEs may have been lower. PRO and RHO were the diets that rendered highest $\mathrm{GGE}_{\text {eggs. }}$. These results indicate that, while PRO was the alga that induced the lowest EPR, it was the one that most efficiently converted ingestion into egg carbon $(\mathrm{GGE}=45 \%$ ). The preferred food, TW, only produced eggs with a $\mathrm{GGE}_{\text {eggs }}=26 \%$.

\section{Egg-hatching success}

Results support the idea that monocultures of different types of algae reduce the viability of eggs, in this case the green flagellate TETRA, and the diatoms TW and DIT to a lesser extent. This result is partially in accordance with earlier reports of enhanced embryonic mortality when females are subject to diatom diets, and higher embryonic viability with Prorocentrum minimum as food (i.e. Turner et al. 2001). For instance, Ban et al. (1997) found Acartia clausi EHS to diminish to $38 \%$ (Skeletonema costatum), $17 \%$ (Phaeodactylum tricornutum), and 25\% (Thalassiosira rotula), but to remain stable when fed Cylindrotheca closterium. However, embryonic mortality in our experiments was never as high as that reported elsewhere for other copepod species (i.e. Poulet et al. 1994, 

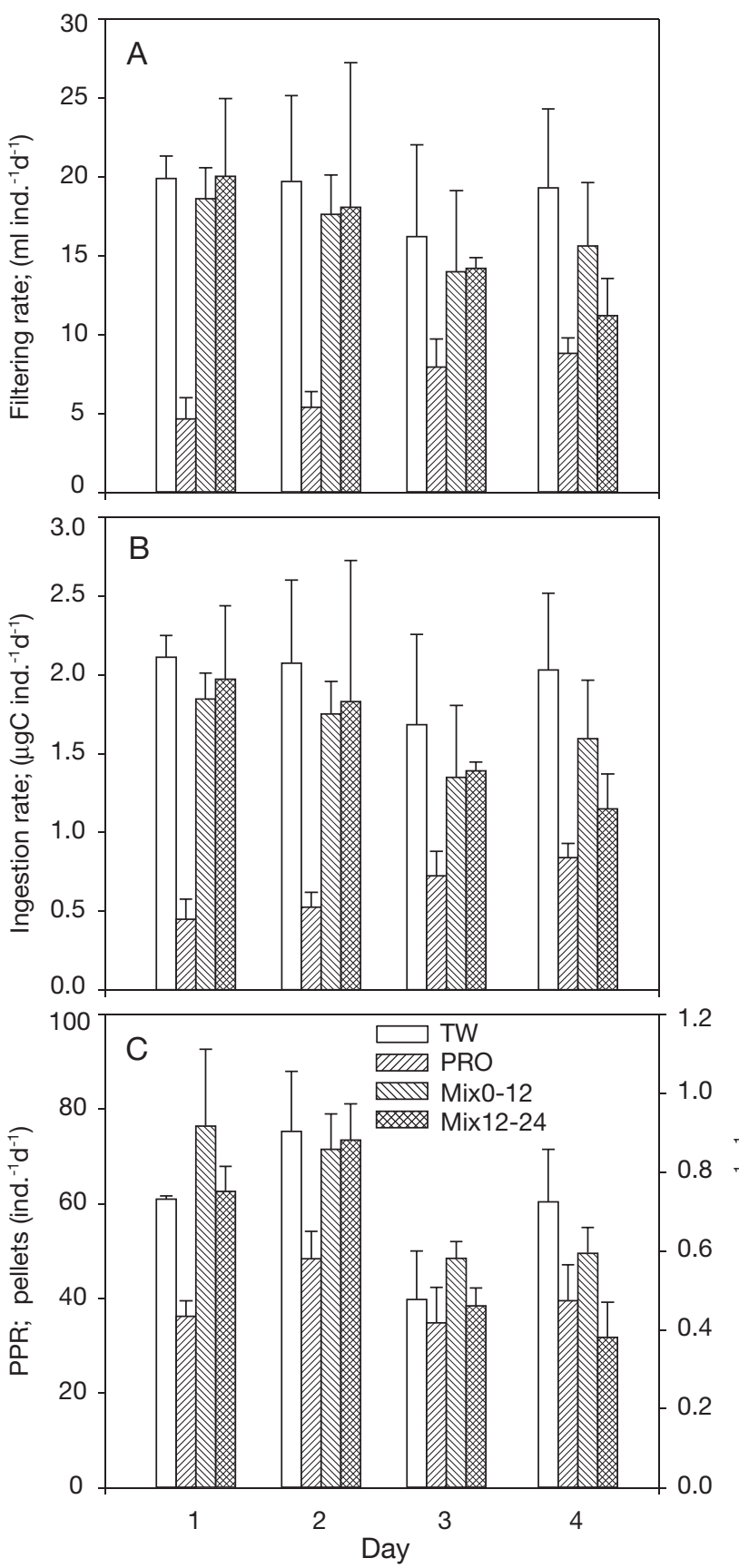

Fig. 4. Acartia clausi. Results from $12 \mathrm{~h}$ incubations in mixedalgae experiments. (A) Filtering rates; (B) ingestion rates; (C) pellet production rates $\mathrm{d}^{-1}$. TW $=$ Thalassiosira weissflogii; $\mathrm{PRO}=$ Prorocentrum minimum $;$ Mix 0-12 = mixed suspension of $50 \%-50 \%$ of $T$. weissflogii and P. minimum in terms of carbon - incubation from midnight to midday; Mix 12-24= mixed suspension of $50 \%-50 \%$ of $T$. weissflogii and P. minimum in terms of carbon-incubation from midday to

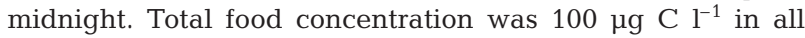

treatments. Error bars represent standard deviations

Kang \& Poulet 2000, Turner et al. 2001). Interestingly, our results show that not only diatoms may reduce EHS, but also the flagellate Tetraselmis sp.
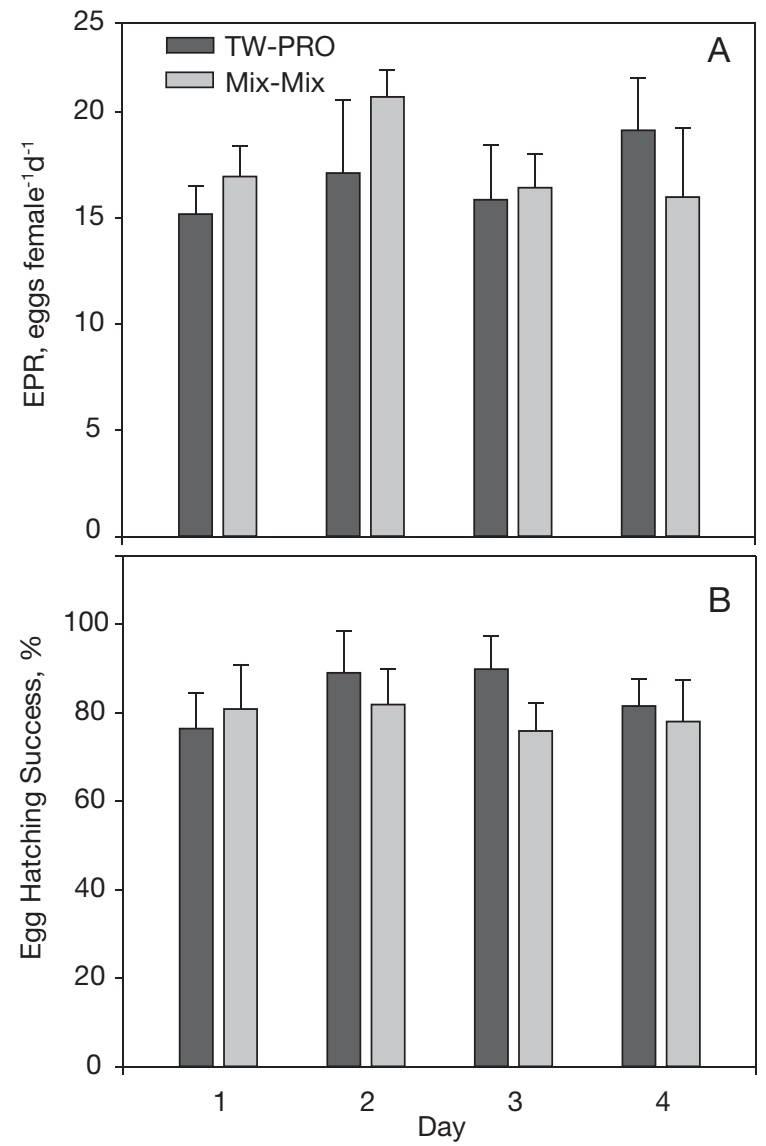

Fig. 5. Acartia clausi. Results from $24 \mathrm{~h}$ incubations in algal mixing experiments. (A) Egg production rate; (B) egg hatching success ( $\%$ of eggs laid). TW-PRO = shifting incubations between single Thalassiosira weissflogii and Prorocentrum minimum algal suspensions; Mix-Mix = shifting incubations between $50 \% \quad$ T. weissflogii and $50 \%$ P. minimum algal suspensions. Shift between algal suspensions were made on a $12 \mathrm{~h}$ basis. Total food concentration was set to $100 \mathrm{\mu g} \mathrm{Cl}^{-1}$ in all suspensions. Error bars represent standard deviations

There is an on-going dispute over negative effects of diatoms. Hatching success in situ is generally high (Irigoien et al. 2002), but exceptions are found (e.g. Miralto et al. 2003). The low hatching success reported by the latter may be due to negative effects of a large temperature difference between EPR and EHS incubations $\left(12\right.$ to $20^{\circ} \mathrm{C}$ ). When in situ temperatures were used for both EPR and EHS, low EHS was rare (Irigoien et al. 2002). Results presented here do no support the contention that embryo development was affected algal toxicity of TW diets. In experiments where copepods were subject to mixed diets with differing effects on EHS (Fig. 5), TW and PRO produced complementary nutritional effects for egg hatchability: mixed diets fall above the reference line connecting 100\% TW and 100\% PRO diets (Jónasdóttir et al. 1998, Colin \& Dam 2002). 


\section{Integrating the food intake}

Acartia clausi was able to integrate the food intake over $24 \mathrm{~h}$ as evidenced by the ALT treatment, which produced EPR, EHS and GGE eggs $_{\text {similar to the MIX or }}$ PRO treatment, but different from the single TW treatment. Furthermore, it seems that even a low quantity of PRO allowed higher EHS than the single TW treatment. In turn, TW favoured higher EPR, but when scaled to the amount of food ingested $\left(\mathrm{GGE}_{\text {eggs }}\right)$, it becomes clear that the outcome is less efficient in relation to PRO and mixed diets. So, A. clausi also benefited from mixed diets in terms of production (Fig. 6), with significantly higher $\mathrm{GGE}_{\text {eggs }}$ compared to the single TW treatment. These results indicate that TW is nutritionally sub-optimal, while still promoting significantly higher ingestion rates.



Fig. 6. Acartia clausi. Mixing diagrams resulting from assembling data from single-alga and mixed-algae experiments. From top to bottom: egg production rate, gross growth efficiency and egg-hatching success (\% of eggs laid); to the left results are plotted vs. the percentage of Thalassiosira weissflogii ingested, and to the right results are plotted vs. the amount of $T$. weissflogii ingested on Day 3. Error bars represent standard deviations
Overall, results showed that none of the algae tested could be considered optimal: PRO yielded highest EHS and $\mathrm{GGE}_{\text {eggs, }}$ but filtering rates on PRO were rather low and EPR response to PRO was lower than average; TW promoted high feeding and EPR, but it was rather sub-optimal for egg viability. Thus, Acartia clausi seems to produce a relatively constant number of viable eggs irrespective of the type of food ingested. The most efficient production occurred with PRO as the single food, as indicated by a GGE eggs $_{\text {of }} 45 \%$. Alternating PRO and TW did not increase EPR (compared to a single TW treatment) or $\mathrm{GGE}_{\text {eggs }}$ (compared to a single PRO treatment) and apparently the copepods are able to integrate different feeding intervals over $24 \mathrm{~h}$. In the MIX treatment, ingestion increased slightly due to a selection for TW over PRO, and this was reflected in a slightly decreased $\mathrm{GGE}_{\text {eggs }}$ while RF remained constant. The single TW diet caused a significantly higher ingestion accompanied by a drastic decrease in EHS and GGE eggs, $_{\text {and }}$ RF remained constant. Thus, it is clear that $A$. clausi can compensate an insufficient diet leading to a low EHS by producing more eggs. This must have strong implications for the survival of the females. Observed PGE outputs strongly suggested qualitative differences among the diverse diets tested, and the action of compensatory behaviour and physiological mechanisms to attain a reasonably balanced RF: compensating low egg survival requires increased feeding, metabolism and predation risk (Tiselius et al. 1997). This is probably not a long-lived strategy, but neither are diatom blooms. Diets in the field are highly variable, and copepod behaviour adds to variability by moving quickly between layers of food. As pointed out by Irigoien et al. (2002), the very low EHS associated with diatom food are generally laboratory findings, and very few negative effects are found in the field. Our results show that a small copepod like Acartia clausi is able to modify its reproductive machinery in response to the type of food ingested on a time scale of 1 to $3 \mathrm{~d}$, and that choosing a 'high-quality' food or mixed diets is very beneficial.

A cautionary note should be introduced regarding the time scale of our experiments, considering the possibility of significantly delayed EHS responses reported even for small copepods $(<7 d$, 
Turner et al. 2001, Shin et al. 2003). If delayed responses existed in the present experiments, our EHS and RF data in single TW and mixed diets could be overestimated by an unquantified amount. However, such a case seems very unlikely here, given the rather stable responses observed in single TW and mixed-diet experiments.

In spite of lower filtration and ingestion rates for PRO, RF was as high as for other food sources with higher filtration rates. The total carbon available to Acartia clausi in our experiments was always $100 \mu \mathrm{g}$ $\mathrm{C}^{-1}$, and $\mathrm{RF}$ was relatively similar, 12.3 to 17.3 viable eggs ind.$^{-1} \mathrm{~d}^{-1}$. This points to a fairly constant transfer efficiency from available food to recruitment, where the modulating factor is the feeding behaviour. Variable filtering rate has implications for survival (Tiselius et al. 1993, 1997), and this is a strong selective force. Recruitment is, however, prioritized, since A. clausi modifies its feeding behaviour to produce as many eggs as possible and still keep a high viable naupliar production. The costs of producing many eggs may be of shorter longevity, but in nature the periods of superfluous food are a small fraction of the life of a copepod.

Could there be any advantage to produce more eggs with a low EHS compared to few with a high viability? Mortality of eggs is very high for broadcast spawners (Kiørboe et al. 1988) and an order of magnitude higher than for nauplii. Egg predation is higher at low food concentration (Saiz et al. 1992), which means that in situations with low food concentration, EHS must be high in order for any EPR to result in recruitment. Copepod recruitment is, however, often coupled to phytoplankton blooms (Kiørboe \& Nielsen 1994), and during these periods with high food concentrations, predation on eggs may decrease. Indeed, the recruitment during blooms may in fact be caused by this decreased mortality. In our experiments, Acartia clausi responded to single diatom food with a high EPR, albeit with a low EHS. This may be a good strategy if egg predation is decreased, since the surviving fraction is still substantial. Most predators on copepod eggs have peak abundances during summer. The peak in predation risk for copepod eggs therefore occurs when water temperature is highest and hatching time shortest. In response to ephemeral diatom blooms in these situations, a high output of eggs with slightly lower EHS and with short hatching times may be a good strategy.

The mixed- and alternating-algae treatments in our study clearly showed that even a modest ingestion of PRO had a significant effect on EHS. It would therefore be rewarding for a copepod to supplement its diet with a non-diatom food source even in times of high EPR. The available food in the field is probably diverse also during blooms, and the capability to search for a mixture should be advantageous. The excellent sensory talents of calanoid copepods are a clear sign of this.
Acknowledgements. We thank M. Appelgren at the Marine Algal Culture Centre (Göteborg University) for providing the algal strains and L. Rodríguez for helping with copepod cultures at KMRS. P. Thor contributed to the discussion of ideas presented here, and 3 anonymous reviewers improved the paper substantially. This study was funded by an Arctic Paper fellowship (Kungliga Vetenskapsakademien) awarded to D.C. for research at KMRS, and by Wåhlströms Foundation to P.T.

\section{LITERATURE CITED}

Ban S, Burns C, Castel J, Chaudron Y, Christou E and 18 others (1997) The paradox of diatom-copepod interactions. Mar Ecol Prog Ser 157:287-293

Berggreen U, Hansen B, Kiørboe T (1988) Food size spectra, ingestion and growth of the copepod Acartia tonsa during development: implications for determination of copepod production. Mar Biol 99:341-352

Bjørnsen PK, Nielsen TG (1991) Decimeter scale heterogeneity in the plankton during a pycnocline bloom of Gyrodinium aureolum. Mar Ecol Prog Ser 73:263-267

Castro L, Bernal PA, González HE (1991) Vertical distribution of copepods and the utilization of the chlorophyll a-rich layer within Concepción Bay, Chile. Estuar Coast Shelf Sci 32:243-256

Chaudron Y, Poulet SA, Laabir M, Ianora A, Miralto A (1996) Is hatching success of copepod eggs diatom densitydependent? Mar Ecol Prog Ser 144:185-193

Colin SP, Dam HG (2002) Testing for toxic effects of prey on zooplankton using sole vs. mixed diets. Limnol Oceanogr 47:1430-1437

Dutz J (1998) Repression of fecundity in the neritic copepod Acartia clausi exposed to the toxic dinoflagellate Alexandrium lusitanicum: relation between feeding and egg production. Mar Ecol Prog Ser 175:97-107

Frost BW (1972) Effect of size and concentration of food particles on the feeding behaviour of the marine planktonic copepod Calanus pacificus. Limnol Oceanogr 17:805-815

Gismervik I., Andersen T (1997) Prey switching by Acartia clausi: experimental evidence and implications of intraguild predation assessed by a model. Mar Ecol Prog Ser 157:247-259

González HE, González S, Brummer GJ (1994) Short term sedimentation patterns of zooplankton, faeces and microplankton at a permanent station in the Bjørnafjorden (Norway) during April-May 1992. Mar Ecol Prog Ser 105: $31-45$

Ianora A, Poulet SA, Miralto A (1995) A comparative study of the inhibitory effect of diatoms on the reproductive biology of the copepod Temora stylifera. Mar Biol 121: 533-539

Ianora A, Poulet SA, Miralto A, Grottoli R (1996) The diatom Thalassiosira rotula affects reproductive success in the copepod Acartia clausi. Mar Biol 125:279-286

Irigoien X, Harris RP, Head RN, Harbour D (2000) The influence of diatom abundance on the egg production rate of Calanus helgolandicus in the English Channel. Limnol Oceanogr 45:1433-1439

Irigoien X, Harris RP, Verheye HM, Pierre J and 14 others (2002) Copepod hatching success in marine ecosystems with high diatom concentrations. Nature 419:387-389

Jónasdóttir SH (1994) Effects of food quality on reproductive success of Acartia tonsa and Acartia hudsonica: laboratory observations. Mar Biol 121:67-81

Jónasdóttir SH, Fields D, Pantoja S (1995) Copepod egg pro- 
duction in Long Island Sound, USA, as a function of the chemical composition of seston. Mar Ecol Prog Ser 119: 87-98

Jónasdóttir SH, Kiørboe T, Tang KW, St. John M, Visser AW, Saiz E, Dam HG (1998) Role of diatoms in copepod production: good, harmless or toxic? Mar Ecol Prog Ser 172: 305-308

Jones RH, Flynn KJ, Anderson TR (2002) Effect of food quality on carbon and nitrogen growth efficiency in the copepod Acartia tonsa. Mar Ecol Prog Ser 235:147-156

Kang HK, Poulet SA (2000) Reproductive success in Calanus helgolandicus as a function of diet and egg cannibalism. Mar Ecol Prog Ser 201:241-250

Kiørboe T, Nielsen TG (1994) Regulation of zooplankton biomass and production in a temperate, coastal ecosystem. I. Copepods. Limnol Oceanogr 39:493-507

Kiørboe T, Sabatini M (1995) Scaling of fecundity, growth, and development in marine planktonic copepods. Mar Ecol Prog Ser 120:285-298

Kiørboe T, Møhlenberg F, Hamburger K (1985) Bioenergetics of the planktonic copepod Acartia tonsa: relation between feeding, egg production and respiration, and composition of specific dynamic action. Mar Ecol Prog Ser 26:85-97

Kiørboe T, Møhlenberg F, Tiselius P (1988) Propagation of planktonic copepods. Production and mortality of eggs. Hydrobiologia 167:219-225

Kleppel GS, Holliday DV, Pieper RE (1991) Trophic interactions between copepods and microplankton: a question about the role of diatoms. Limnol Oceanogr 36:172-178

Mauchline J (1998) The biology of copepods. Adv Mar Biol 33: $1-710$

Miralto A, Barone G, Romano G, Poulet SA and 7 others (1999) The insidious effect of diatoms on copepod reproduction. Nature 402:173-176

Miralto A, Guglielmo L, Zagami G, Buttino I, Granata A, Ianora A (2003) Inhibition of population growth in the copepods Acartia clausi and Calanus helgolandicus during diatom blooms. Mar Ecol Prog Ser 254:253-268

Müller-Navarra D, Brett MT, Park S, Chandra S, Ballantyne AP, Zorita E, Goldman CR (2003) Unsaturated fatty acid content in seston and tropho-dynamic coupling in lakes.

Editorial responsibility: Thomas Kiørboe (Contributing Editor), Charlottenlund, Denmark
Nature 427:69-72

Mullin MM, Sloan PR, Eppley RW (1966) Relationship between carbon content, cell volume and area in marine phytoplankton. Limnol Oceanogr 11:307-311

Poulet SA, Ianora A, Miralto A, Meijer L (1994) Do diatoms arrest embryonic development in copepods? Mar Ecol Prog Ser 111:79-86

Poulet SA, Laabir M, Ianora A, Miralto A (1995) Reproductive response of Calanus helgolandicus. I. Abnormal embryonic and naupliar development. Mar Ecol Prog Ser 129: 85-95

Saiz E, Alcaraz M, Paffenhöfer GA (1992) Effects of smallscale turbulence on feeding rate and gross-growth efficiency of three Acartia species (Copepoda: Calanoida). J Plankton Res 14:1085-1097

Shin K, Jang MC, Jang PK, Ju SJ, Lee TK, Chang M (2003) Influence of food quality on egg production and viability of the marine planktonic copepod Acartia omorii. Prog Oceanogr 57:265-277

Stearns D, Tester P, Walker R (1989) Diel changes in the egg production rate of Acartia tonsa (Copepoda, Calanoida) and related environmental factors in two estuaries. Mar Ecol Prog Ser 52:7-16

Tester PA, Turner JT (1990) How long does it take copepods to make eggs? J Exp Mar Biol Ecol 141:169-182

Tiselius P, Jonsson PR, Verity PG (1993) A model for the evaluation of the impact of food patchiness on foraging strategy and predation risk in zooplankton. Bull Mar Sci 53: $247-264$

Tiselius P, Jonsson PR, Kaartvedt S, Olsen EM, Jørstad T (1997) Effects of copepod foraging behaviour on predation risk: an experimental study of the predatory copepod Paraeuchaeta norvegica feeding on Acartia clausi and A. tonsa (Copepoda). Limnol Oceanogr 42:164-170

Turner JT, Ianora A, Miralto A, Laabir M, Esposito F (2001) Decoupling of copepod grazing rates, fecundity and egg hatching success on mixed and alternating diatom and dinoflagellate diets. Mar Ecol Prog Ser 220:187-199

Uye S (1982) Length-weight relationships of important zooplankton from the Inland Sea of Japan. J Oceanogr Soc Jpn 38:149-158

Submitted: December 23, 2004; Accepted: April 20, 2005 Proofs received from author(s): July 26, 2005 